\title{
Which, Tourniquet or Inflation of Blood Pressure Cuff, can Dilate Peripheral Vein Adequately for Intravenous Access?
}

\author{
Jun Xiong ${ }^{1}$, Huijun Wang ${ }^{2}$, Pengfei Zhan ${ }^{1}$, Yimei Ding ${ }^{1}$, Yin Bao ${ }^{2}$, Cunliang Ji², Feng Mu ${ }^{1}$ and Yongxing \\ Sun $^{1 *}$ \\ ${ }^{1}$ Department of Anesthesiology, Sanbo Brain Hospital, Capital Medical University No.50, Yikesong, Xiangshan, Haidian District, Beijing, \\ 100093, China
}

${ }^{2}$ Department of Anesthesiology, Tongren Hospital, Capital Medical University, No.1 Dongjiao minxiang, Dongcheng District, Beijing, 100730, China

Jun Xiong and Huijun Wang contributed equally to this study and have been regarded as co-first author

*Corresponding author: Yongxing Sun, Department of Anesthesiology, Sanbo Brain Hospital, Capital Medical University, No. 50,

Yikesong, Xiangshan, Haidian District, Beijing, 100093, China

\section{ARTICLE INFO}

Received: 音 July 11, 2019

Published: 蔧 July 26, 2019

Citation: Jun Xiong, Huijun Wang, Pengfei Zhan, Yimei Ding, Yin Bao, Cunliang J, Feng M, Yongxing Sun. Which, Tourniquet or Inflation of Blood Pressure Cuff, can Dilate Peripheral Vein Adequately for Intravenous Access?. Biomed J Sci \& Tech Res 20(1)-2019. BJSTR. MS.ID.003398.

Keywords: Tourniquet; Intravenous; Antecubital Vein; Visual Analogue Scale; Ultrasonography; Peripheral

\begin{abstract}
Objectives: Peripheral intravenous access is a common clinical procedure. It is wellknown that venodilation improves success rate of peripheral intravenous cannulation. Elastic tourniquet and blood pressure cuff are frequently applied to dilate peripheral veins. The objective of this study is to evaluate which maneuvers designed to dilate antecubital veins are more effective.

Methods: This was a prospective non-random trail enrolling fifty healthy volunteers. Ultrasound was used to select an antecubital vein as a target vein. Its' diameter and cross-section area were measured sonograghically at the same position with different maneuvers, that was baseline, elastic tourniquet and blood pressure cuff with different inflation pressure. The blood pressure cuff was inflated with pressure from $30 \mathrm{mmHg}$ to $120 \mathrm{mmHg}$, in $30 \mathrm{mmHg}$ increments. Time-intervals between each maneuver were longer enough and basic measurements were repeated to ensure the target vein recover to initial state. At the same time, volunteers' subjective feeling and degrees of tight under different maneuvers were recorded and evaluated by Visual Analogue Scale. Comparisons among different maneuvers were performed by Repeated Measurement test and Bonferroni test. Non-parametric test Kruskal-Wallis One-Way ANOVA was used to pairwise compare differences of volunteers' scores of Visual Analogue Scale. The differences of diameter and cross-section area between right and left arm were evaluated by Paired-Sample test.
\end{abstract}

Results: All maneuvers dilated diameters and cross-section areas of target antecubital veins significantly from baseline $(\mathrm{P}=0.000)$. Target veins were dilated most significantly by blood pressure cuff with $60 \mathrm{mmHg}$ inflation pressure $(\mathrm{P}=0.000)$. Blood pressure cuff with $90 \mathrm{mmHg}$ inflation pressure resulted in the second largest increase in target vein size $(\mathrm{P}=0.000)$. Although there were no significant differences between blood pressure cuff with inflation of $30 \mathrm{mmHg}$ and $120 \mathrm{mmHg}$ pressure $(\mathrm{P}=1.000)$, elastic tourniquet significantly increases diameters and cross-section areas of target vein size when compared to them $(\mathrm{P}=0.000)$. Scores of Visual Analogue Scale of elastic tourniquet and blood pressure cuff with $120 \mathrm{mmHg}$ inflation pressure were not significantly different $(\mathrm{P}=0.581)$, but these were significantly higher than other maneuvers $(\mathrm{P}=0.000)$.

Blood pressure cuff with $30 \mathrm{mmHg}$ inflation pressure significantly decreased the score of Visual Analogue Scale, when compared with maneuvers of $60 \mathrm{mmHg}$ and $90 \mathrm{mmHg}$ inflation pressure. Nevertheless, there was no significant difference between the scores of $60 \mathrm{mmHg}$ and $90 \mathrm{mmHg}$ inflation pressure $(\mathrm{P}=0.369)$. The differences of baseline of 
diameter and cross-section area between right and left arm were not statistically significant $(\mathrm{P}=0.359$ and $\mathrm{P}=0.404$ respectively). The diameter and cross-section area of target veins were correlative to different maneuvers $(\mathrm{P}=0.000)$, but not to Right-Left side $(\mathrm{P}=0.828$ and $\mathrm{P}=0.609$ respectively). The venodilation effectiveness of different maneuvers on right and left side was similar to their general effectiveness, which not split by right and left side.

Conclusion: Although elastic tourniquet and blood pressure cuff dilated antecubital veins, blood pressure cuff with $60 \mathrm{mmHg}$ inflation pressure was the most effective, followed by $90 \mathrm{mmHg}$ inflation pressure. And blood pressure cuff was more comfortable and tolerable than elastic tourniquet when dilating vein for successful peripheral vein access establishment. Venodilation effectiveness of different maneuvers was same on right and left side. Right and left antecubital veins were not obvious different for peripheral intravenous access.

\section{Background}

Intravenous access (IVA) is one of the most common clinical procedures in healthcare, particularly for patients in emergency department, operating room, intensive care unit, and so on. However, establishing IVA is a challenge, particularly in pediatric and geriatric patients with fragile or hidden veins [1]. Difficult IVA results in need for multiple needle insertion. Studies have demonstrated that vein filling or vein size is an important predictor of successful peripheral venipuncture and/or cannulation [2,3], especially in patients with difficult access. Although central venous puncture and cannulation is not bad choice to patients with difficult IVA, this procedure requires staff resources and medical cost, the more important is that central venous catheter is with more complication risks [4,5].

How to make peripheral vein dilation to facilitate IV access? An elastic tube as tourniquet is the most maneuver, which induces venous stasis for cannulation, such as basilica vein on elbow and saphenous vein on ankle. Although effective, elastic tube might cause discomfort and some complications.

Except elastic tourniquet (ET), most monitors used in clinic provide a function of IVA assistance. With a blood pressure cuff (BPC), an exact pressure is set to prevent peripheral vein collapse during puncture and cannulation. But also, the BPC would be deflated automatically after completing venipuncture. Some studies researched this venodilation effectiveness of ET and BPC, but their conclusions are inconsistent $[6,7]$.

The objective of this study is to assess the effectiveness of venous dilation with different clinical maneuvers commonly available in operating room. Meanwhile ultrasound is utilized to evaluate an appropriate pressure range to increase vein filling.

\section{Methods}

This was a prospective non-randomized trial, which was approved by the ethics committee of Sanbo Brain Hospital, Capital Medical University. And all methods were performed in accordance with the relevant guidelines and regulations. Healthy volunteers were enrolled over a 2-month period (March to April 2019). Sanbo Brain Hospital is a tertiary care facility, level one neurosurgery center and academic center for training neurosurgeon nationwide. All volunteers were required to sign written informed consent.

Lower limb deep vein thrombosis has received more attention in public awareness recently, which has been researched and welldescribed as a common condition. But upper limb thrombosis is a less common phenomenon comparing with lower limb. Risk factors for limb thrombosis include any injury to vein intima, venous stasis, and so on [8]. So in our hospital, upper limb is superior to lower limb for IVA, this was why upper limb was researched in our study. Meanwhile, there are several safe and suitable sites on arm for appropriate venipuncture and cannulation, such as cephalic vein, median cubital vein and basilic vein [9]. The exclusive criteria were as follow: history of upper limb thrombosis, history of upper limb surgery, upper extremity malformation and/or fracture, upper limb infection or venipuncture within three months, any acute medical illness, pregnancy, prior intravenous drug abuse. If these exclusive criteria present in only one upper extremity, the unaffected contralateral one could be still included in this study. Warmer temperature has been well-known to increase peripheral vein size and improve success of IVA [10]. Then all volunteers were observed in a same temperature-humidity-controlled operating room throughout their exposure to all different maneuvers.

Antecubital vein of each volunteers were identified using a high frequency linear probe $(4.0 \sim 16.0 \mathrm{MHz}, 10 \mathrm{I} 2$ probe on a SonoScape E3, SonoScape Medical Corporation. Shenzhen, Guangdong Province, China.). Detection depth was set at $2 \mathrm{~cm}$. If there were more veins on fossa cubitalia, the largest one was selected. After basic diameter of antecubital veins was obtained, putting the image of target vein on the middle of screen, skin marks were made along the middle of two edges of probe. And upper limbs were kept at the level of heart and same posture during every maneuver. All of these attentions ensured measurements under the same condition.

Antecubital vein measurements of each maneuver included anterior-posterior diameter and cross-section area (CSA), using short-axis image of the target vein (Figure 1). Because veins might 
not be standard circular, so both diameter and CSA were together observed to identify changes of the target vein under different maneuvers. Each volunteer's measurement was obtained following procedure: firstly, basic diameter and area were measured, followed by measurements of diameter and area with ET. Next, the second and third volunteers would be measured same parameters. After that, the three volunteers' diameter and area of the target vein under BPC with $30 \mathrm{mmHg}$ inflation pressure were measured one by one. After the maneuver of $30 \mathrm{mmHg}$ inflation pressure was finished, the strength would be raised to $120 \mathrm{mmHg}$ with $30 \mathrm{mmHg}$ increments, and the measurement procedure was repeated one by one. The target vein should return to baseline size between each different maneuver. By this procedure, there was enough time to ensure the target vein returning to primitive level, because inadequate recovery time would produce result bias [11]. Meanwhile basic measurement of target vein was repeated before each maneuver to determine its' restoration. The detail BPC inflation pressure was set by a monitor with a function of auxiliary IVA (Mindray BeneView T8, Shenzhen Mindray Bio-Medical Electronics Co., Ltd. Shenzhen, Guangdong Province, China). BPC was single-use disposable (Figure 2).

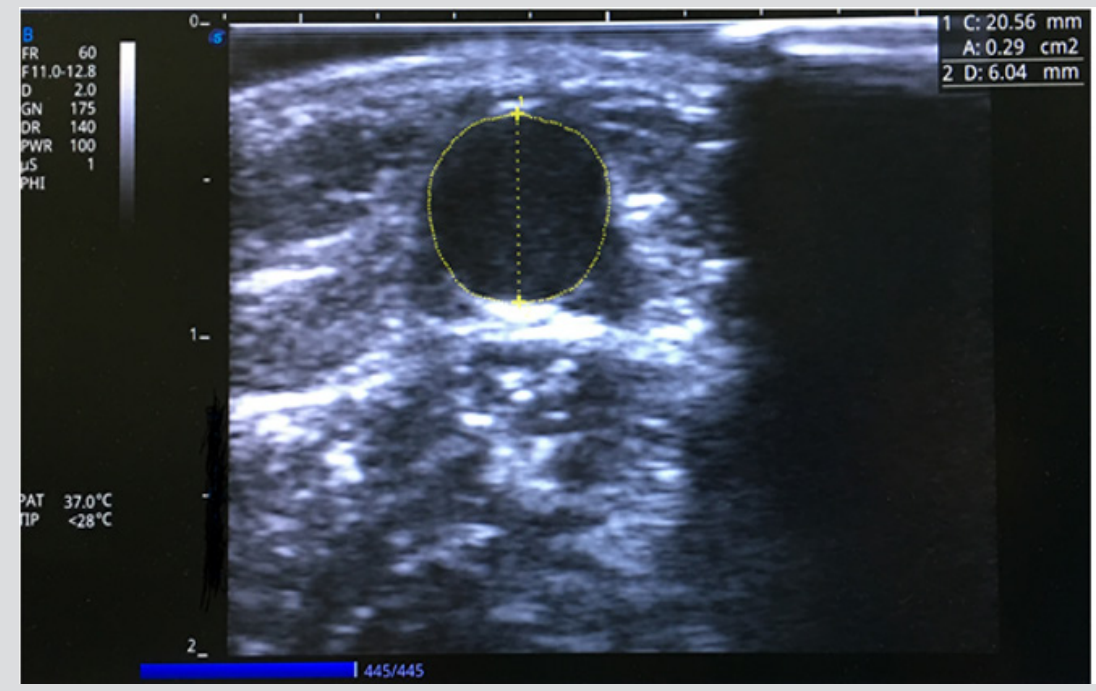

Figure 1: The diameter and cross-section area of antecubital vein.

This was an ultrasound image of antecubital vein with measurement of anterior-posterior diameter (D: 6.04mm) and crosssection area $\left(\mathrm{A}: 0.29 \mathrm{~cm}^{2}\right)$.

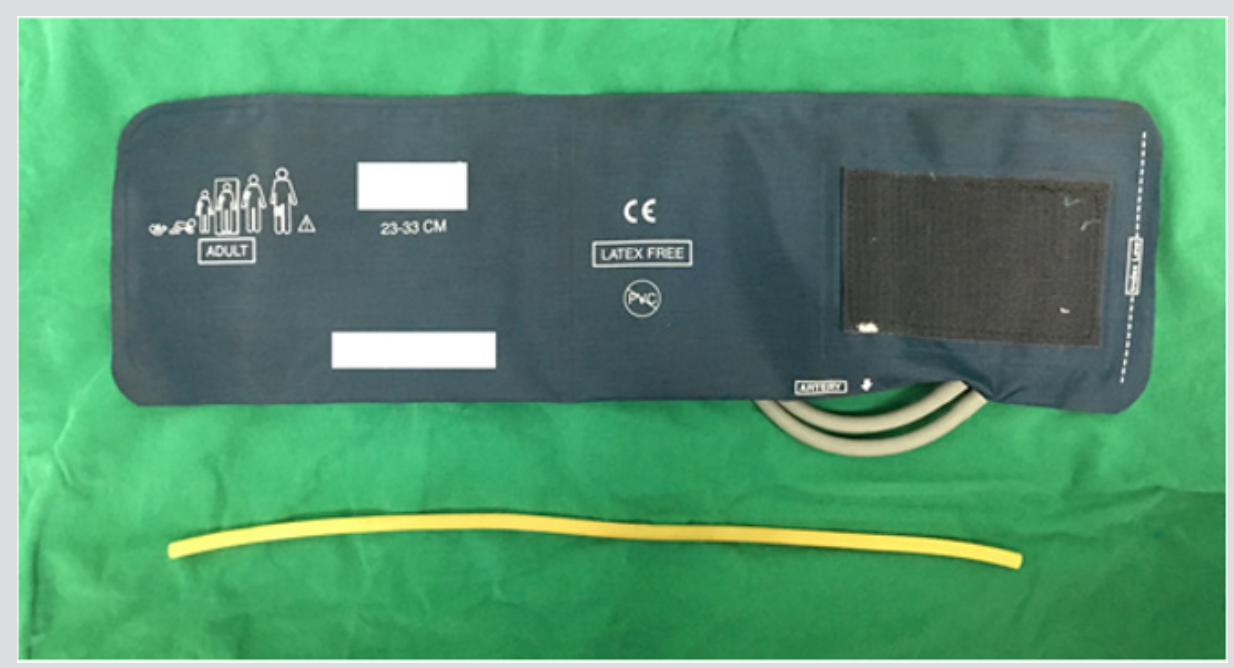

Figure 2: The photo of elastic tourniquet and blood pressure cuff.

All measurements were started at 20 seconds after each maneuver implementation, furthermore the measurement duration was controlled within 30 seconds. Because vein dilated gradually until 30 seconds after BPC inflation. At the same time, longer duration of tourniquet or BPC strapping could increase hemolysis rate and induce movement of water and low molecular weight substances across well of vein. So strapping time within 35 to 60 seconds should be strongly suggested [12-14]. 
During the process, all volunteers were asked to complete a questionnaire, which including 4 questions related to volunteers' subjective feeling with different maneuvers (Table 1). Volunteers' degree of comfort was evaluated with Visual Analogue Scale (VAS) because it was convenient and valuable [15]. Ultrasound equipment operation and sonographic measurement were completed by a senior anesthetist, who received ultrasound training more than two years. A senior nurse did tourniquet strapping throughout whole trail of data acquisition. Using the data obtained above, average vein diameters and areas were calculated.

Table 1: The Questionnaire for Elastic Tourniquet and Blood Pressure Cuff.

\begin{tabular}{|c|c|c|c|c|c|c|}
\hline \multicolumn{4}{|c|}{$\begin{array}{c}\text { Whether do you consider elastic tourniquet the more tight the more effective when you strap it for } \\
\text { peripheral intravenous cannulation }\end{array}$} & \multirow{2}{*}{$\begin{array}{c}\text { YES } \\
60 \mathrm{mmHg}\end{array}$} & \multirow{2}{*}{$\begin{array}{c}\text { NO } \\
90 \mathrm{mmHg}\end{array}$} & \multirow{2}{*}{$\begin{array}{l}\text { Uncertain } \\
120 \mathrm{mmHg}\end{array}$} \\
\hline \multirow{4}{*}{$\begin{array}{l}\text { Which maneuver is much tighter than } \\
\text { elastic tourniquet? }\end{array}$} & & ET & $30 \mathrm{mmHg}$ & & & \\
\hline & loose & & & & & \\
\hline & similar & & & & & \\
\hline & tight & & & & & \\
\hline \multirow{2}{*}{$\begin{array}{l}\text { Which maneuver is more comfortable } \\
\text { than elastic tourniquet? }\end{array}$} & comfort & & & & & \\
\hline & discomfort & & & & & \\
\hline Please score for each maneuve & VAS & & & & & \\
\hline
\end{tabular}

Note: VAS: Visual Analogue Score. From 0 to 10, different number stands for the degree of pain. 0 stands for analgia and 10 stands for baryodynia.

\section{Statistical Analysis}

IBM SPSS Statistics version 21 (Armonk, NY, USA: IBM Corp) was used to perform statistical analysis. Quantitative data were expressed as mean \pm standard deviation $(\chi 2 \pm$ SD). Normal distribution of data was check by Kolmogorov-Smirnov analysis. Repeated Measurement was used for general comparison of all maneuvers. Bonferroni was used to pairwise comparisons between all maneuvers. If data were non-normal distribution, those were expressed as [median (quartile)]. Nonparametric Kruskal-Wallis was applied for general comparison of all maneuvers, and KruskalWallis one-way ANOVA was for pairwise comparisons of different maneuvers. Paired-Samples test was applied for comparisons of diameter and CSA of right and left sides. $\mathrm{P}<0.05$ was considered to indicate statistics significance.

\section{Results}

Over 2 months study 100 antecubital veins of 50 healthy volunteers had been measured. The age of volunteers was $33.20 \pm 7.61$ years, their size was $170.70 \pm 7.37 \mathrm{~cm}$, and their bodyweight was 68.82 $\pm 13.17 \mathrm{~kg}$. 13 (26\%) were female and 37 (74\%) were male. Based on their sizes and weight, their calculated BSA was $1.80 \pm 0.20$. Their SBP, DBP and MAP were $110.68 \pm 11.38 \mathrm{mmHg}$, $66.62 \pm 9.68 \mathrm{mmHg}$ and $79.16 \pm 9.82 \mathrm{mmHg}$ respectively.

In this study, Mauchly's Test of Sphericity showed $\chi 2=119.837$, $\mathrm{P}=0.000$ and $\mathrm{G}-\mathrm{G} \varepsilon=0.606$ for diameters, meanwhile $\chi 2=136.92$, $\mathrm{P}=0.000$ and $\mathrm{G}-\mathrm{G} \varepsilon=0.564$ for CASs. Diameters (Roy's Largest Root, $\mathrm{F}=96.596, \quad \mathrm{P}=0.000$ ) and CSAs (Roy's Largest Root, $\mathrm{F}=64.821$
, $\mathrm{P}=0.000$ ) of the target veins were significantly different with different maneuvers. Results of tests of within-subjects' effects were $\mathrm{F}=201.592, \mathrm{P}=0.000$ (Greenhouse-Geisseer) for diameter, meanwhile $\mathrm{F}=162.334, \mathrm{P}=0.000$ (Greenhouse-Geisseer) for CSAs respectively. It was confirmed again that diameters and CSAs of the target vein were generally significantly different with different maneuvers. Whatever ET or BPC with different inflation pressures, diameters (Bonferroni, $\mathrm{P}=0.000$ ) and CSAs (Bonferroni, $\mathrm{P}=0.000$ ) of the target veins were increased significantly when compared with basic diameters and CSAs of the target veins. BPC with $60 \mathrm{mmHg}$ and $90 \mathrm{mmHg}$ inflation pressure significantly increased diameters (Bonferroni, $\mathrm{P}=0.000$ ) and CSAs (Bonferroni, $\mathrm{P}=0.000$ ) of the target veins when compared to ET. However, diameters (Bonferroni, $\mathrm{P}=0.000$ ) and CSAs (Bonferroni, $\mathrm{P}=0.000$ ) of these veins with ET were significantly larger than those of BPC with $30 \mathrm{mmHg}$ and $120 \mathrm{mmHg}$ inflation pressure. Although diameters and CSAs of the target veins were not significantly different between BPC with $30 \mathrm{mmHg}$ and $120 \mathrm{mmHg}$ inflation pressure (Bonferroni, $\mathrm{P}=1.000$ ), these diameters (Bonferroni, $\mathrm{P}=0.000$ ) and CSAs (Bonferroni, $\mathrm{P}=0.000$ ) were increased significantly by BPC with $60 \mathrm{mmHg}$ and $90 \mathrm{mmHg}$ inflation pressure when compared with $30 \mathrm{mmHg}$. The diameters (Bonferroni, $\mathrm{P}=0.000$ ) and CSAs (Bonferroni, $\mathrm{P}=0.000$ ) of BPC with $120 \mathrm{mmHg}$ inflation pressure were significantly less than those of BPC with $60 \mathrm{mmHg}$ and $90 \mathrm{mmHg}$ inflation pressure. Although BPC with $60 \mathrm{mmHg}$ inflation pressure could produce much larger diameters and CSAs than those of $90 \mathrm{mmHg}$ inflation pressure, only the difference of CSAs was significant between them (Bonferroni, P=0.037) (Tables $2 \& 3$ ) (Figure 3). 


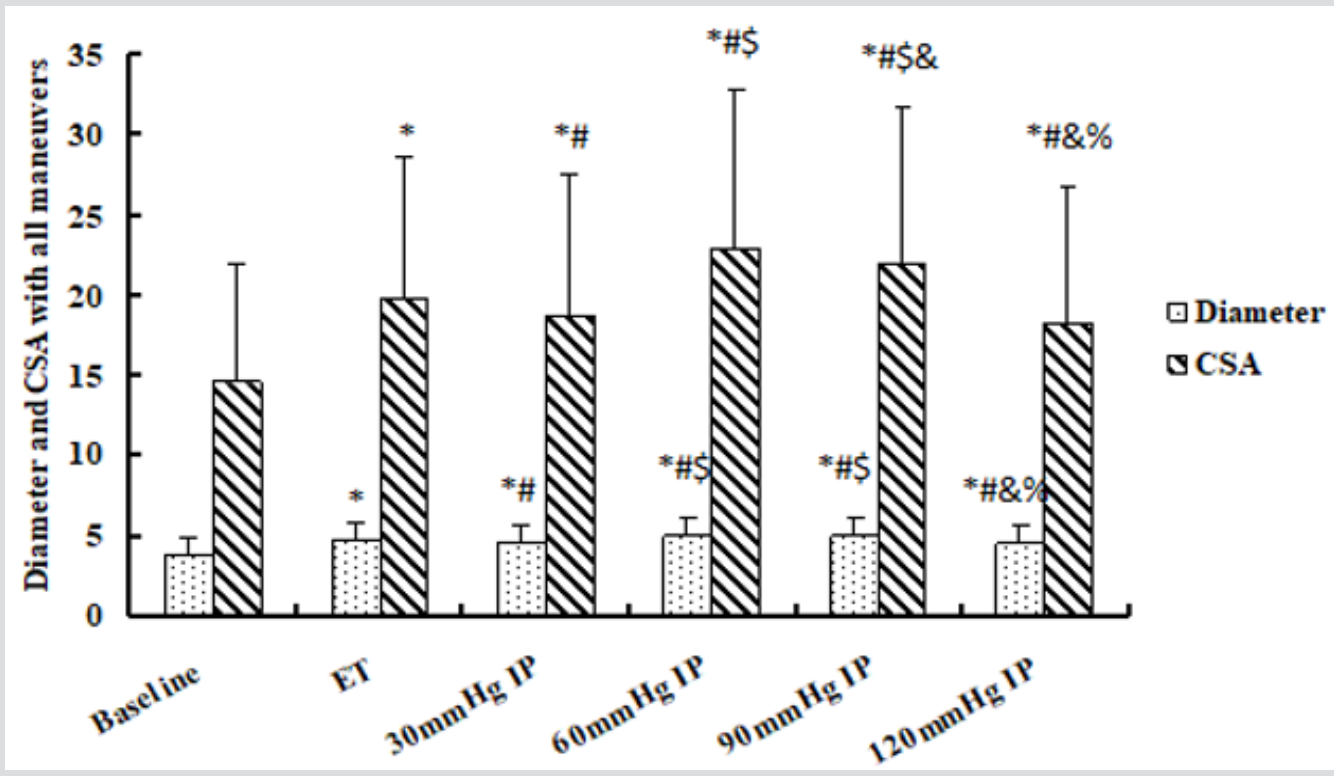

Figure 3: The diameter and cross-section area of antecubital vein under different maneuvers.

CSA: Cross-Section Area. ET: Elastic tourniquet. IP: Inflation pressure. * Compared to baseline, all maneuvers increased diameters and CSAs significantly. \# The diameter and CSA of ET were significantly larger than those of BPC with $30 \mathrm{mmHg}$ and $120 \mathrm{mmHg}$ inflation pressure. However, they were significantly less than those of BPC with $60 \mathrm{mmHg}$ and $90 \mathrm{mmHg}$ inflation pressure. \$ Although there were no significantly different dimeter and CSA between BPC with $30 \mathrm{mmHg}$ and $120 \mathrm{mmHg}$ inflation pressure, venodilation of them was significantly weaker than that of BPC with $60 \mathrm{mmHg}$ and $90 \mathrm{mmHg}$ inflation pressure. \& The diameter and CSA of BPC with $60 \mathrm{mmHg}$ inflation pressure were larger than these of BPC with $90 \mathrm{mmHg}$ and $120 \mathrm{mmHg}$ inflation pressure, but there was no significant difference of diameters between BPC with $60 \mathrm{mmHg}$ and $90 \mathrm{mmHg}$. $\%$ The diameter and CSA of BPC with $90 \mathrm{mmHg}$ were significantly larger than these of $120 \mathrm{mmHg}$ inflation pressure.

Table 2: Diameters and Cross-section Areas of all maneuver.

\begin{tabular}{|c|c|c|}
\hline & Diameter (mm) & Cross-section Area (mm $\mathbf{~}^{\mathbf{}}$ ) \\
\hline Baseline & $3.79 \pm 1.07$ & $14.63 \pm 7.30$ \\
\hline Elastic tourniquet & $4.60 \pm 1.08$ & $19.83 \pm 8.89$ \\
\hline BPC 30mmHg & $4.44 \pm 1.11$ & $18.71 \pm 8.90$ \\
\hline BPC $60 \mathrm{mmHg}$ & $4.94 \pm 1.09$ & $22.93 \pm 9.97$ \\
\hline BPC 90mmHg & $4.89 \pm 1.08$ & $22.04 \pm 9.64$ \\
\hline BPC 120mmHg & $4.44 \pm 1.07$ & $18.32 \pm 8.48$ \\
\hline
\end{tabular}

Table 3: All pairwise comparisons of maneuvers by One-Way Repeated Measurement.

\begin{tabular}{|c|c|c|c|c|c|c|c|}
\hline \multirow[b]{2}{*}{ Maneuver A } & \multirow[b]{2}{*}{ Maneuver B } & \multicolumn{3}{|c|}{ Diameter (mm) } & \multicolumn{3}{|c|}{ Cross-section area $\left(\mathrm{mm}^{2}\right)$} \\
\hline & & $\begin{array}{l}\text { (A-B)Mean } \\
\text { Difference }\end{array}$ & $\begin{array}{l}95 \% \text { CI for } \\
\text { Difference }\end{array}$ & $\mathrm{P}$ & $\begin{array}{c}(\mathrm{A}-\mathrm{B}) \text { Mean } \\
\text { Difference in }\end{array}$ & $\begin{array}{l}95 \% \text { CI for } \\
\text { Difference }\end{array}$ & $\mathrm{P}$ \\
\hline Baseline & ET & -0.813 & -0.967 to -0.659 & 0.000 & -5.200 & -6.290 to -4.110 & 0.000 \\
\hline Baseline & $30 \mathrm{mmHg}$ & -0.649 & -0.802 to -0.495 & 0.000 & -4.080 & -5.169 to- 2.991 & 0.000 \\
\hline Baseline & $60 \mathrm{mmHg}$ & -1.154 & -1.333 to -0.974 & 0.000 & -8.300 & -9.868 to -6.732 & 0.000 \\
\hline Baseline & $90 \mathrm{mmHg}$ & -1.101 & -1.271 to -0.931 & 0.000 & -7.410 & -8.764 to- 6.056 & 0.000 \\
\hline Baseline & $120 \mathrm{mmHg}$ & -0.655 & -0.817 to -0.493 & 0.000 & -3.690 & -4.744 to -2.636 & 0.000 \\
\hline ET & $30 \mathrm{mmHg}$ & 0.164 & 0.061 to 0.268 & 0.000 & 1.120 & $0 . .507$ to 1.733 & 0.000 \\
\hline ET & $60 \mathrm{mmHg}$ & -0.340 & -0.444 to -0.236 & 0.000 & -3.100 & -4.002 to -2.198 & 0.000 \\
\hline ET & $90 \mathrm{mmHg}$ & -0.288 & -0.388 to -0.187 & 0.000 & -2.210 & -2.989 to -1.431 & 0.000 \\
\hline ET & $120 \mathrm{mmHg}$ & 0.158 & 0.044 to 0.272 & 0.001 & 1.510 & $0 . .739$ to 2.281 & 0.000 \\
\hline $30 \mathrm{mmHg}$ & $60 \mathrm{mmHg}$ & -0.505 & -0.602 to -0.408 & 0.000 & -4.220 & -5.172 to -3.268 & 0.000 \\
\hline $30 \mathrm{mmHg}$ & $90 \mathrm{mmHg}$ & -0.452 & -0.545 to -0.359 & 0.000 & -3.330 & -4.154 to -2.506 & 0.000 \\
\hline $30 \mathrm{mmHg}$ & $120 \mathrm{mmHg}$ & -0.006 & -0.104 to 0.092 & 1.000 & 0.390 & -.339 to 1.119 & 1.000 \\
\hline
\end{tabular}




\begin{tabular}{|c|c|c|c|c|c|c|c|}
\hline $60 \mathrm{mmHg}$ & $90 \mathrm{mmHg}$ & 0.052 & -0.025 to 0.129 & 0.659 & 0.890 & 0.028 to 1.752 & 0.037 \\
\hline $60 \mathrm{mmHg}$ & $120 \mathrm{mmHg}$ & 0.499 & 0.393 to 0.604 & 0.000 & 4.610 & 3.607 to 5.613 & 0.000 \\
\hline $90 \mathrm{mmHg}$ & $120 \mathrm{mmHg}$ & 0.446 & 0.345 to 0.548 & 0.000 & 3.720 & -4.548 to -2.892 & 0.000 \\
\hline
\end{tabular}

Note: $\mathrm{P}$ value and $95 \%$ confidence interval have been adjusted for multiple comparisons using Bonferroni method. The mean difference is significant at 0.05 level.

The scores of VAS with different maneuvers were significantly different in general (Kruskal-Wallis, $\mathrm{P}=0.000$ ). There was no significant difference of VAS scores between ET and BPC with $120 \mathrm{mmHg}$ inflation pressure (adjusted $\mathrm{P}=0.581$ ), however the scores of both maneuvers were significantly higher than scores of BPC with

$30 \mathrm{mmHg}, 60 \mathrm{mmHg}$ and $90 \mathrm{mmHg}$ inflation pressures (adjusted $\mathrm{P}=0.000$ ). Scores of BPC with $60 \mathrm{mmHg}$ and $90 \mathrm{mmHg}$ inflation pressures were not significantly different (adjusted $\mathrm{P}=0.369$ ), but these scores were significantly increased comparing to BPC with $30 \mathrm{mmHg}$ inflation pressure (adjusted $\mathrm{P}=0.000$ ) (Table 4).

Table 4: The subjective feeling and VAS of all maneuvers.

\begin{tabular}{|c|c|c|c|c|c|c|}
\hline \multirow{2}{*}{ Maneuver } & \multicolumn{3}{|c|}{ Degree of tight $(n=50)$} & \multicolumn{2}{|c|}{ Subjective feeling $(n=50)$} & \multirow{2}{*}{ VAS } \\
\hline & loose & similar & tight & Comfort & Discomfort & \\
\hline Elastic Tourniquet & & & & 0 & 50 & {$[7(6,7.25)]$} \\
\hline BPC with 30mmHg & 50 & 0 & 0 & 50 & 0 & {$[1(1,1)]^{*}$} \\
\hline BPC with $60 \mathrm{mmHg}$ & 0 & 50 & 0 & 50 & 0 & {$[3(3,4)]^{* \# \&}$} \\
\hline BPC with $90 \mathrm{mmHg}$ & 0 & 50 & 0 & 50 & 0 & {$[4(4,5)]^{* \# \&}$} \\
\hline BPC with $120 \mathrm{mmHg}$ & 0 & 3 & 47 & 45 & 5 & {$[8(7,8)] \#$} \\
\hline
\end{tabular}

Note: VAS: Visual Analogue Scale. *Compare to ET, VAS scores of BPC with $30 \mathrm{mmHg}, 60 \mathrm{mmHg}$ and $90 \mathrm{mmHg}$ inflation pressures were significantly decreased. \#VAS scores of BPC with $60 \mathrm{mmHg}, 90 \mathrm{mmHg}$ and $120 \mathrm{mmHg}$ inflation pressure were significantly higher than that of $30 \mathrm{mmHg}$ inflation pressure. \&VAS score of BPC with $120 \mathrm{mmHg}$ inflation pressure was significantly increased, compared with these of $60 \mathrm{mmHg}$ and $90 \mathrm{mmHg}$ inflation pressure.

By Paired-Samples test, the differences between basic diameter and CSA of right and left target veins were not statistically significant $(\mathrm{P}=0.359$ and $\mathrm{P}=0.404$ respectively). Venodilation effectiveness of different maneuvers on right and left antecubital veins was analyzed with Two-Way Repeated Measurement test. Mauchly's Test of Sphericity showed $\chi 2=75.866, P=0.000$ and G-G $\varepsilon=0.620$ for intercept of maneuvers and right-left on diameters of target veins, and $\chi 2=57.531, \mathrm{P}=0.000$ and $\mathrm{G}-\mathrm{G} \varepsilon=0.614$ for intercept of maneuvers and right-left on CSAs of target veins. The intercept of maneu-

vers and right-left on diameters and CSAs of target veins were not significantly $(\mathrm{F}=0.674, \mathrm{P}=0.574$ and $\mathrm{F}=0.776, \mathrm{P}=0.512$ respectively). Meanwhile diameters and CSAs of target veins were correlative with different maneuvers $(\mathrm{F}=192.586, \mathrm{P}=0.000$ and $\mathrm{F}=0.265$, $\mathrm{P}=0.609$ respectively) but not with right-left $(\mathrm{F}=0.048, \mathrm{P}=0.828$ and $\mathrm{F}=165.530, \mathrm{P}=0.000$ respectively). By Bonferroni pairwise comparison, venodilation effectiveness of different maneuvers on right and left sides was as same as their general venodilation effectiveness, which was not separated by right and left (Table 5) (Figures $4 \& 5$ ).

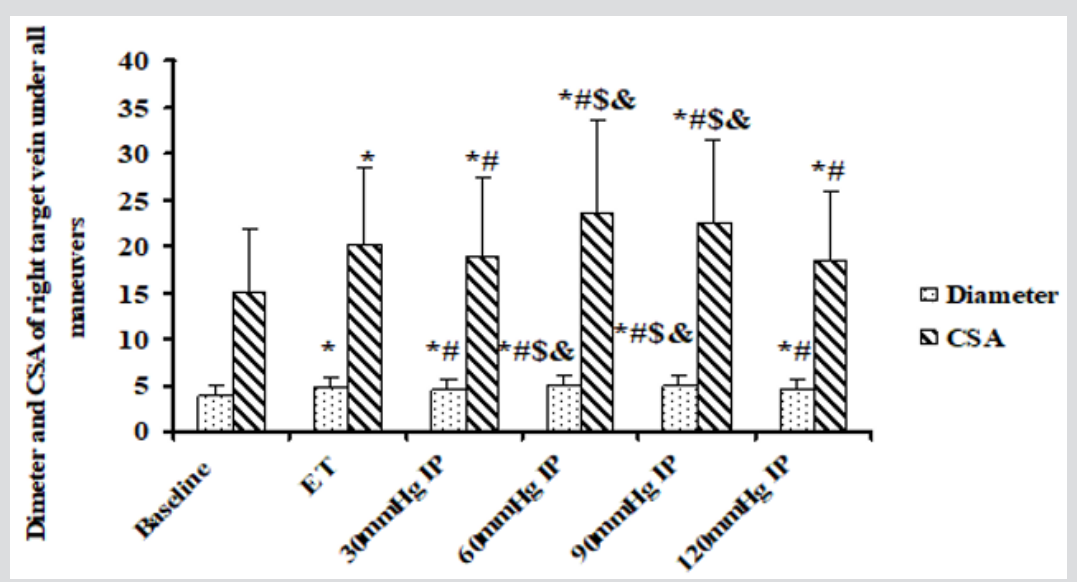

Figure 4: The diameter and CSA of right target veins with all maneuvers.

CSA: Cross-Section Area. ET: Elastic tourniquet. IP: Inflation pressure. * Compared to baseline, all maneuvers increased diameters and CSAs significantly. \# The diameter and CSA of ET were significantly larger than those of BPC with $30 \mathrm{mmHg}$ and $120 \mathrm{mmHg}$ inflation pressure. However, they were significantly less than those of BPC with $60 \mathrm{mmHg}$ and $90 \mathrm{mmHg}$ inflation pressure. \$ Although there were no significantly different dimeter and CSA between BPC with $30 \mathrm{mmHg}$ and $120 \mathrm{mmHg}$ inflation pressure, venodilation of them was significantly weaker than that of BPC with $60 \mathrm{mmHg}$ and $90 \mathrm{mmHg}$ inflation pressure. \& The diameter and CSA of BPC with $60 \mathrm{mmHg}$ and $90 \mathrm{mmHg}$ inflation pressure were larger than these of BPC with $120 \mathrm{mmHg}$ inflation pressure 


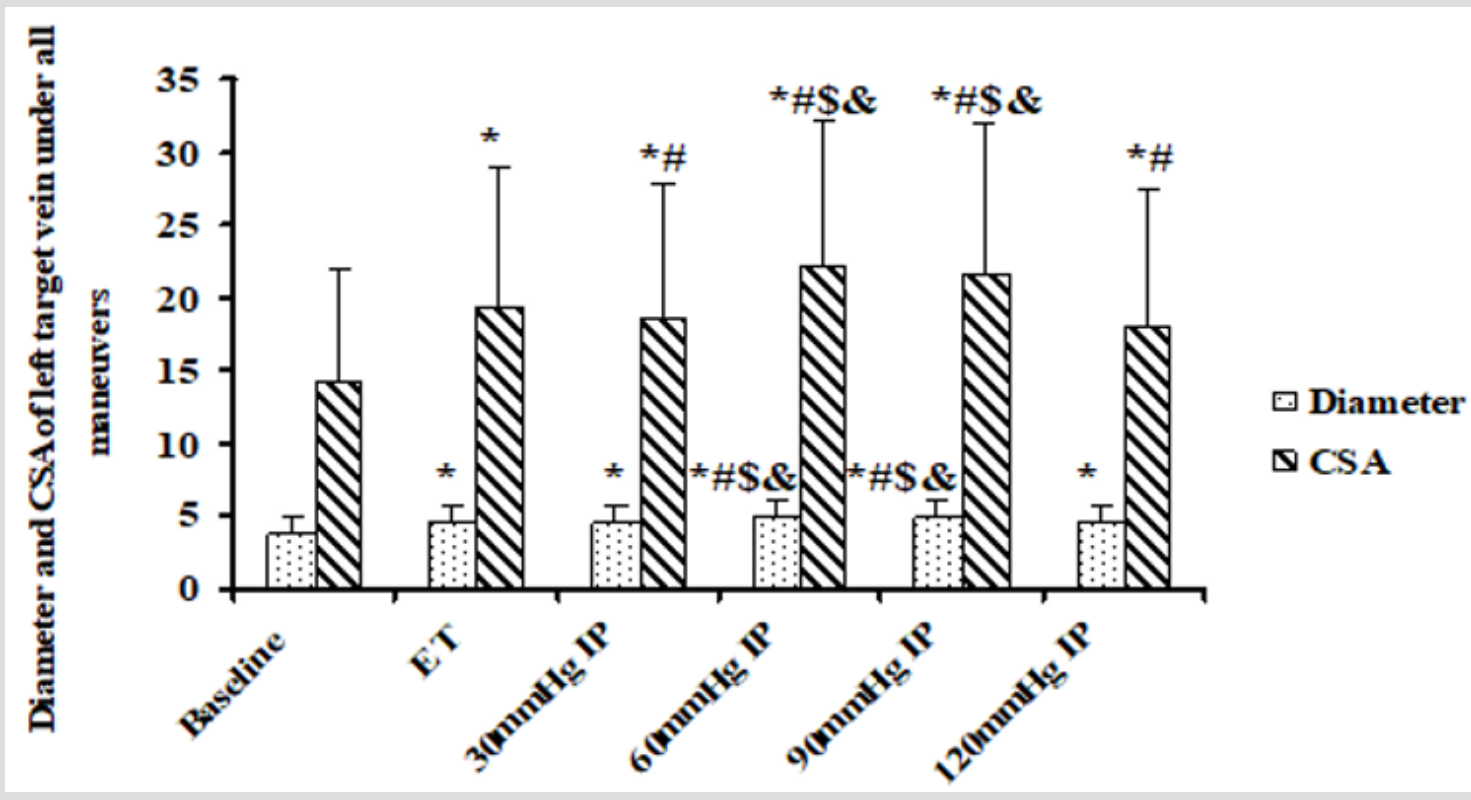

Figure 5: The diameter and CSA of left target vein with all maneuvers.

CSA: Cross-Section Area. ET: Elastic tourniquet. IP: Inflation pressure. * Compared to baseline, all maneuvers increased diameters and CSAs significantly. \# The dianmeter and CSA of ET were significantly less than those of BPC with $60 \mathrm{mmHg}$ and $90 \mathrm{mmHg}$ inflation pressure. Although CSA of ET was significantly larger then that of BPC with $30 \mathrm{mmHg}$ and $120 \mathrm{mmHg}$, the diameter was not significantly statistical different between them. \$ Although there were no significantly different diameter and CSA between BPC with $30 \mathrm{mmHg}$ and $120 \mathrm{mmHg}$ inflation pressure, venodilation of them was significantly weaker than that of BPC with $60 \mathrm{mmHg}$ and $90 \mathrm{mmHg}$ inflation pressure. \& The diameter and CSA of BPC with $60 \mathrm{mmHg}$ and $90 \mathrm{mmHg}$ inflation pressure were larger than these of BPC with $120 \mathrm{mmHg}$ inflation pressure.

Table 5: The diameters and CSAs of right and left antecubital veins.

\begin{tabular}{|c|c|c|c|c|}
\hline & \multicolumn{2}{|c|}{ Right } & \multicolumn{2}{c|}{ Left } \\
\hline Maneuver & Diameter $(\mathbf{m m})$ & CSA $\left(\mathbf{m m}^{\mathbf{}}\right)$ & Diameter $(\mathbf{m m})$ & CSA $\left(\mathbf{m m}^{2}\right)$ \\
\hline Baseline & $3.84 \pm 1.05$ & $15.02 \pm 6.81$ & $3.74 \pm 1.09$ & $14.24 \pm 7.80$ \\
\hline Elastic tourniquet & $4.63 \pm 1.03$ & $20.20 \pm 8.35$ & $4.57 \pm 1.13$ & $19.44 \pm 9.49$ \\
\hline 30mmHg inflation pressure & $4.45 \pm 1.04$ & $18.88 \pm 8.62$ & $4.43 \pm 1.20$ & $18.54 \pm 9.25$ \\
\hline 60mmHg inflation pressure & $4.94 \pm 1.03$ & $23.66 \pm 10.05$ & $4.95 \pm 1.16$ & $22.18 \pm 9.97$ \\
\hline 90mmHg inflation pressure & $4.88 \pm 1.02$ & $22.46 \pm 8.95$ & $4.90 \pm 1.16$ & $21.58 \pm 10.41$ \\
\hline $120 \mathrm{mmHg}$ inflation pressure & $4.46 \pm 0.99$ & $18.50 \pm 7.53$ & $4.43 \pm 1.15$ & $18.14 \pm 9.42$ \\
\hline
\end{tabular}

Note: CSA: Cross-section Area

\section{Discussion}

In this study all maneuvers, whatever ET or BPC with different inflation pressures, resulted in statistically significant dilation of antecubital veins, including increasement of vein diameter and CSA. Among all maneuvers, BPC with $60 \mathrm{mmHg}$ inflation pressure was the most effective to dilate target vein. BPC with $90 \mathrm{mmHg}$ inflation pressure also increased vein sizes significantly, but its' effectiveness was inferior to BPC with $60 \mathrm{mmHg}$ inflation pressure. The venodilation of ET was less than that of BPC with $60 \mathrm{mmHg}$ and $90 \mathrm{mmHg}$ inflation pressure, however it was stronger than that of BPC with $30 \mathrm{mmHg}$ and $120 \mathrm{mmHg}$ inflation pressure. As to BPC with $30 \mathrm{mmHg}$ and $120 \mathrm{mmHg}$, their function of filling vein was similar and inferior to the three formers. All volunteers considered BPC with $60 \mathrm{mmHg}$ and $90 \mathrm{mmHg}$ inflation pressure were as same tight as ET, but they were more comfortable than ET. Although scores of VAS of ET was similar to BPC with $120 \mathrm{mmHg}$ inflation pressure, their scores were much higher than these of BPC with $60 \mathrm{mmHg}$ and $90 \mathrm{mmHg}$ inflation pressure. Basic diameter and CSA of right and left were similar. And changes of them were dependent on different maneuvers, not on right and left sides.

ET is universally used in nationwide clinic to fill vein for peripheral IVA. Actually, it is able to increase venodilation and decrease compressibility. In this study, ET increased target vein diameter $0.81 \mathrm{~mm}(21 \%)$ and CSA $5.2 \mathrm{~mm}^{2}$ (36\%) comparing to basic value. These results were consistent with previous study. Mahler and colleague [11] reported ET increased diameter of vein $0.71 \mathrm{~mm}$ from the baseline, about $14 \%$. The difference between ours and Mahler's might be caused by different volunteers' races. For example, the mean diameter of basilic vein in Mahler's study was $5.1 \mathrm{~mm}$. However, the mean diameter of antecubital vein was 
just $3.79 \mathrm{~mm}$, and these were the largest antecubital veins selected in our study. Actually these slight differences could not deny ET was an easy method for peripheral vein distention. This explained why ET was prevalent for IVA.

In fact, venodilation effectiveness of ET was inferior to inflation of BPC [11]. Beyond that, there are other disadvantages of ET for venodiation. Because it is slim and much externally narrower area contacting with skin, it could cause sharp pain and discomfort. This was identified by our study. All volunteers felt discomfort when ET was strapped on arm, even though the strapping time was very transient. When BPC was inflated with $60 \mathrm{mmHg}$ and $90 \mathrm{mmHg}$ pressure, although volunteers felt the degree of tight was similar to that of ET, they still considered BPC was more comfortable and tolerable than ET. Actually, that VAS score of BPC lower than ET's also verified BPC was more tolerable than ET.

For ET, the more serious complication is tourniquet retention. A tourniquet may be inadvertently left in limbs for long time after an attempt to IVA. Although serious damage is rare, this might cause infiltration, edema, nerve damage, and so on [16]. We have to pay attention to these complications to avoid adverse events, because they were undoubted to produce additional hospital stay and medical expenses. This could not happen as to BPC because of its automatic deflation.

Given tourniquet material and repeated use in clinical setting these reusable tourniquets are considered as a source of microbiological contamination. If without adequate reprocessing of sterilization, reuse of tourniquet might jeopardize patients' safety [17] In 2018 Petersen and colleague reported hygiene of venipuncture tourniquets in Denmark. Their investigation indicated that there was lack of standard procedures or guidelines for handling of venipuncture tourniquets in their nation. Thus, these non-sterile tourniquets used on multiple patients was the potential risk of a nosocomial infection [18]. It is unknown whether there are similar guidelines in our nation, but it does exist in our hospital. However, another problem arises because repeated sterilization discounts ET's effectiveness of venous distension.

Contemporary monitors provide auxiliary function for venipuncture. With BPC inflation, it is able to attain a detail pressure to make veins more visible or palpable. Furthermore, single-use disposable BPC might avoid transmission of pathogenic bacteria as a kind of medium. But when establishing peripheral IVA or cannualtion, inflated BPC is not used as frequently as ET. The detail reason had not been known, perhaps ET might be easy and convenient. Additional most enrolled volunteers did not learn this function of monitor.

In our study BPC was not only increased venodilation, but also its effectiveness was much stronger than ET's. BPC inflating with $60 \mathrm{mmHg}$ inflation pressure could increase target vein diameter $1.15 \mathrm{~mm}(30 \%)$ and CSA $8.3 \mathrm{~mm}^{2}$ (57\%) from baseline respectively. When inflating with $90 \mathrm{mmHg}$ pressure, its' effectiveness was similar to $60 \mathrm{mmHg}$ inflation pressure, especially their diameters were no significant statistical different. These results were consistent with the previous study. Mahler indicated that inflated BPC produced the largest increasement in basilica vein size compared to ET. In their study BPC was inflated with a pressure above volunteer's diastolic pressure [11], however authors did not note the detail diastolic pressure. In our study the mean diastolic pressure of volunteers was $66.62 \mathrm{mmHg}$, thus the most remarkable vein distensions were exactly produced by $60 \mathrm{mmHg}$ to $90 \mathrm{mmHg}$ inflation pressure. And inflated BPC demonstrated much stronger venodilation than ET due to more obvious change of vein size. But there were some differences between the two studies about detail value of diameter. We inferred that different volunteer's race might cause the deviation between two studies, in addition, inadequate recovery time might attenuate the capability of dilation of veins. Thus, the different sequence of maneuvers was designed to ensure adequate vein recovery time.

Our results were consistent with another previous study too. In 2012 Sasaki and colleague researched the relationship of BPC inflation pressure and CSA of forearm vein. They demonstrated that CSA of forearm superficial vein increased with BPC strength from $40 \mathrm{mmHg}$ to $80 \mathrm{mmHg}$. Above $100 \mathrm{mmHg}$, CSA would be conversely decreased [12]. These were very close to ours that the most suitable inflation pressures were $60 \mathrm{mmHg}$ and $90 \mathrm{mmHg}$. When inflation pressure was above $90 \mathrm{mmHg}$, diameter and CSA of target vein would be decreased to the level of $30 \mathrm{mmHg}$ inflation pressure, even be inferior to the level of ET. Therefore, it was expected that the more BPC strength the more dilation of vein, but this did not occur. Actually, all volunteers enrolled were asked whether the more tourniquet strength the larger vein size. Interestingly all of them gave a negative answer, however they did not learn the most appropriate pressure or strength for IVA, they just answered intuitively.

Some studies compared venidilation function of BPC and tourniquet in difficult stick patients, but these conclusions were contradictory. For instance, Nelson showed that ET was superior to BPC for target vein distension, which inflated with $150 \mathrm{mmHg}$ inflation pressure [6]. Under same inflation pressure, Kule and colleague supported utilization of BPC for peripheral venous annulation, because the compressibility of peripheral vein was decreased significantly not by tourniquet but by BPC [7]. However, there were different evaluation criterions applied in these two studies. According to our results, these contradictory conclusions might be caused by an inappropriate inflation pressure. Inflating with too high pressure not only decreased vein's size but also patients' tolerance and comfort $[11,12]$.

Why venodilation effectiveness of BPC was discounted when inflated with more than $120 \mathrm{mmHg}$ pressure? We inferred BPC not only made vein distension, but also blocked arterial flow obviously if inflation pressure more than 120mmHg. In 2013 the study of Liu and colleague demonstrated the inflation pressure 
blocking arterial flow on upper limb was $152 \mathrm{mmHg}$, which was much less than previously recommended 250 to $300 \mathrm{mmHg}$. In their study, SPB of healthy volunteers was $115 \pm 13 \mathrm{mmHg}$ and DPB $67 \pm 8 \mathrm{mmHg}$ [19]. These results were very close to ours, which were $110.68 \pm 11.38 \mathrm{mmHg}$ and $66.62 \pm 9.68 \mathrm{mmHg}$ respectively. Thus, we inferred that if inflation pressure was more than $150 \mathrm{mmHg}$, arterial flow of upper limb would be blocked. It was undoubted there would be more blood if without arterial occlusion. This might be an explanation why venodilation effectiveness of BPC would be discounted when inflation pressure was more than $120 \mathrm{mmHg}$. And it might explain why ET was superior to BPC with more than $150 \mathrm{mmHg}$ inflation pressure for vein dilation, because the strength of ET might be less than 120mmHg inflation pressure. Our study provided proof because the degree of tight between ET and BPC with $60 \mathrm{mmHg}$ and $90 \mathrm{mmHg}$ was not different. But these would need future study.

Our study showed ET dilated target veins to $4.60 \mathrm{~mm}$, and BPC with $60 \mathrm{mmHg}$ inflation pressure dilated those veins to $4.94 \mathrm{mmHg}$. The difference between these two maneuvers was just $0.34 \mathrm{~mm}$. If inflated with $90 \mathrm{mmHg}$ pressure, the difference would be less far. Whether could this slight difference be translated into clinical mean? Actually, in clinic, both ET and BPC perform similar venodilation for successful peripheral intravenous cannulation [20]. Nevertheless, this was not paradoxical with above results, BPC with $60 \mathrm{mmHg}$ and $90 \mathrm{mmHg}$ inflation pressure did increase the vein size significantly, just because the difference between ET and BPC was too small to be clinically significant.

Our results demonstrated there were no significant different basic diameters and CSAs between right and left antecubital veins. For analyzing effects of different maneuvers on these right and left veins, Two-Way Repeated Measurement test was used. The results were extremely similar to the above general results which not split by right-left. Changes of diameter and CSA of the target veins were not associated with Right-Left but with different maneuvers. The target veins were dilated most significantly by BPC with $60 \mathrm{mmHg}$ and $90 \mathrm{mmHg}$ inflation pressure, followed by ET. And the venodilation effectiveness of BPC with $30 \mathrm{mmHg}$ and $120 \mathrm{mmHg}$ inflation pressure was the weakest. One maneuver produced same venodilation on right and left target veins. In other words, there was no difference for selecting IVA sites on right or left arm.

However, some studies showed the different results with ours. For example, Choden considered left hand was better than right hand for peripheral intravenous insertion [21]. And Jones used ultrasound observed saphenous vein on both sides. The diameter of left saphenous vein was significantly larger than that of right one [22]. Although the sizes of both sides in our study were not statistically significant, diameter of right vein was slight larger than that of left vein. Increasing sample and comparing the same vein might resolve these differences between studies. All volunteers enrolled in our study were Right-hand people, this might be additional reason.
In clinic, establishing peripheral IVA can be a challenge for nurses sometimes. Multiple unsuccessful attempts for IVA might have negative impacts on patients and practitioners [23]. So, given impacts of a peripheral IVA on patients' clinical outcomes and cost implication, reducing the failed attempts should be of high importance [21]. Actually, many factors affect success rate of first IVA. For instance, previous history of a difficult IVA, clinicians' great confidence and experience, IVA site, and so on [20,24-25]. However, the palpability and diameter of peripheral vein might be more important than others [3,24-25]. In the present study, whatever ET or BPC increased diameter of these veins larger than $4 \mathrm{~mm}$. If diameter of target vein was larger than $4 \mathrm{~mm}$, it would improve first peripheral IVA success rate [3]. Except ET and BPC, local IVA site warming is a safe and effective method for venodilation [10]. All in all, healthcare providers should apply alternative techniques or combine these techniques to improve the first success rate of IVA.

\section{Limitation}

Because volunteers enrolled were young and healthy, rather than patients with previous history of difficult IVA, so this conclusion should be discreetly promoted in clinic. If patients after long intensive care unit stay or in end-stage renal disease, the condition of their peripheral veins would be much poor. Planken's study indicated that mean diameter of forearm superficial vein was only $1.8 \mathrm{~mm}$ in patients of end-stage renal disease [26]. Although these diameters were measured under tourniquet or BPC, they were only half of ours. For these patients, there is needed further study.

\section{Conclusion}

Both ET and BPC resulted in a statistically significant increase in antecubital vein size. BPC with $60 \mathrm{mmHg}$ inflation pressure produced the largest venodilation, followed by $90 \mathrm{mmHg}$ inflation pressure. When BPC inflation pressure was more than $120 \mathrm{mmHg}$, its' effectiveness of venodilation would be discounted. The detail reason of this attenuation should be investigated in future. There was no obvious difference for right and left antecubital veins as IVA site due to their similar size and reaction to BPC. Because BPC was much more comfortable and tolerable, it should be recommended in clinic and combined with other venodilation techniques for more successful IVA.

\section{Volunteer Consent}

Written informed consent was obtained from all study volunteers.

\section{Authors' Contribution}

JX, HJW and YXS were involved in the study design, statistical analysis and manuscript preparation. PFZ and YMD were involved in the study design and carrying out study measurements. YB and CLJ provided statistical support. FM was involved in manuscript preparation. All authors read and approved the manuscript. 


\section{Competing interests}

The authors declare that they have no competing interests.

\section{Acknowledgment}

We would like to thank all participants for their cooperation in this study.

\section{References}

1. Fukuroku K, Narita Y, Taneda Y, Kobayashi S, Gayle AA, et al. (2016) Does infrared visualization improve selection of venipuncture sites for indwelling needle at the forearm in second-year nursing students? Nurse Educ Pract 18: 1-9.

2. Panebianco NL, Fredette JM, Szyld D, Sagalyn EB, Pines JM, et al. (2009) What you see (sonographically) is what you get: vein and patient characteristics associated with successful ultrasound-guided peripheral intravenous placement in patients with difficult access. Acad Emerg Med 16(12): 1298-1303.

3. Witting MD, Schenkel SM, Lawner BJ, Euerle BD (2010) Effects of vein width and depth on ultrasound-guided peripheral intravenous success rates. J Emerg Med 39(1): 70-75.

4. Chinnock B, Thornton S, Hendey GW (2007) Predictors of success in nurse-performed ultrasound-guided cannulation. J Emerg Med 33(4): 401-405.

5. Steele R, Irvin CB (2001) Central line mechanical complication rate in emergency medicine patients. Acad Emerg Med 8(2): 204-207.

6. Nelson D, Jeanmonod R, Jeanmonod D (2014) Randomized trial of tourniquet vs blood pressure cuff for target vein dilation in ultrasoundguided peripheral intravenous access. Am J Emerg Med 32(7): 761-764.

7. Kule A, Hang B, Bahl A (2014) Preventing the collapse of a peripheral vein during cannulation: an evaluation of various tourniquet techniques on vein compressibility. J Emerg Med 46(5): 659-666.

8. Chen AWY, Oraii Yazdani K, Candilio L (2018) Upper Limb Deep Vein Thrombosis: A Case Report of an Increasingly Common Condition. J Tehran Heart Cent 13(2): 73-75.

9. Mukai K, Nakajima Y, Nakano T, Okuhira M, Kasashima A, et al. (2017) Safety of Venipuncture Sites at the Cubital Fossa as Assessed by Ultrasonography. J Patient Saf.

10. Yamagami Y, Tomita K, Tsujimoto T, Inoue T (2017) Tourniquet application after local forearm warming to improve venodilation for peripheral intravenous cannulation in young and middle-aged adults: A single-blind prospective randomized controlled trial. Int J Nurs Stud 72: 1-7.

11. Mahler SA, Massey G, Meskill L, Wang H, Arnold TC, et al. (2011) Can we make the basilica vein larger? Maneuvers to facilitate ultrasound guided peripheral intravenous access: a prospective cross-sectional study. Int J of Emerg Med 4: 53-57.

12. Sasaki S, Murakami N, Matsumura Y, Ichimura M, Mori M, et al. (2012) Relationship between tourniquet pressure and a cross-section area of superficial vein of forearm. Acta Med Okayama 66(1): 67-71.

\section{ISSN: 2574-1241}

DOI: $10.26717 /$ BJSTR.2019.20.003398

Yongxing Sun. Biomed J Sci \& Tech Res

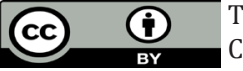

This work is licensed under Creative Commons Attribution 4.0 License

Submission Link: https://biomedres.us/submit-manuscript.php
13. Phelan MP, Reineks EZ, Schold JD, Hustey FM, Chamberlin J, et al. (2018) Preanalytic Factors Associated with Hemolysis in Emergency Department Blood Samples. Arch Pathol Lab Med. 142(2): 229-235.

14. Lima Oliveira G, Lippi G, Salvagno GL, Montagnana M, Picheth G, et al. (2013) The effective reduction of tourniquet application time after minor modification of the CLSI03-A6 blood collection procedure. Biochem Med (Zagred) 23(3): 308-315.

15. Voutilainen A, Pitkäaho T, Kvist T, Vehviläinen Julkunen K (2016) How to ask about patient satisfaction? The visual analogue scale is less vulnerable to confounding factors and celling effect than a symmetric Likert scale. J Adv Nurs 72(4): 946-957.

16. Mattox EA (2017) Complications of Peripheral Venous Access Devices: Prevention, Detection, and Recovery Strategies. Crit Care Nurse 37(2): e1-e14.

17. Salgueiro Oliveira AS, Costa PJDS, Braga LM, Graveto JMGN, Oliveira VS, et al. (2019) Health professionals' practices related with tourniquet use during peripheral venipuncture: a scoping review. Rev Lat Am Enfermagem 27: e3125.

18. Petersen ERB, Nybo M (2018) Hygiene of venepuncture tourniquets in Denmark. Scand J Clin Lab Invest 78(5): 417-420.

19. Liu HY, Guo JY, Zhang ZB, Li KY, Wang WD (2013) Development of adaptive pneumatic tourniquet systems based on minimal inflation pressure for upper limb surgeries. Biomed Eng Online 12: 92.

20. Tran T, Lund SB, Nichols MD, Kummer T (2019) Effect of two tourniquet techniques on peripheral intravenous cannulation success: A randomized controlled trial. Am J Emerg Med S0735-6757(19): 3018330184.

21. Choden J, Carr PJ, Brock AR, Esterman A (2019) Nurse performed peripheral intravenous catheter first time insertion success in pediatric patients in Bhutan: An observational study. J Vasc Access 20(2): 184189.

22. Jones T, Stea N, Stolz U, Adhikari S (2015) Ultrasound evaluation of saphenous vein for peripheral intravenous cannulation in adults. J Vasc Access 16(5): 418-421

23. Asrar M, Al Habaibeh A, Shakmak B, Shaw SJ (2018) A device for improving the visual clarity and dimension of veins. Br J Nurs 27(19): S26-S36.

24. Carr PJ, Rippey JCR, Cook ML, Trevenen ML, Higgins NS, et al. (2019) Factors associated with peripheral intravenous cannulation firsttime insertion success in the emergency department. A multicentre prospective cohort analysis of patient, clinician and product characteristics. BMJ Open 9(4): e022278.

25. Yalçınlı S, Akarca FK, CanÖ, Şener A, Akbinar C, et al. (2019) Factors affecting the first-attempts success rate of intravenous cannulation in older people. J Clin Nurs 28(11-12): 2206-2213.

26. Planken RN, Keuter XH, Hoeks AP, Kooman JP, Van Der Sande FM, et al. (2006) Diameter measurement of the forearm cephalic vein prior to vascular access creation in end-stage renal disease patients: graduated pressure cuff versus tourniquet vessel dilatation. Nephrol Dial Transplant 21(3): 802-806.

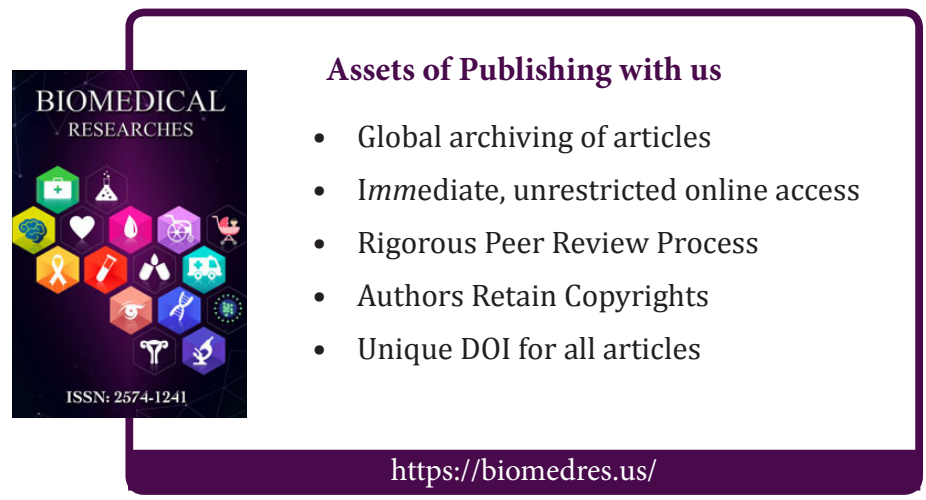

Copyright@ Yongxing Sun | Biomed J Sci \& Tech Res | BJSTR. MS.ID.003398. 